\title{
Static calculations in the context of sewer pipe sliplining by polymer hose
}

\author{
Oleg Primin* and Vladimir Orlov \\ Moscow State University of Civil Engineering, Yaroslavskoe shosse, 26, Moscow, 129337, Russia
}

\begin{abstract}
The growing deterioration and unsatisfactory technical condition of the pipes of water supply and wastewater disposal networks in Russian cities and other inhabited localities, as well as limited (under the conditions of Russian housing and utilities sector reforming) funding of pipeline renovation and rehabilitation have considerably aggravated the problem of pipe reliability provision. These factors make pipe renovation and rehabilitation quite a topical issue. A very promising trend in the field of pipeline construction and renovation named "trenchless technologies" has been commonly used in the world in recent years. A wide choice of different construction materials used for pipe rehabilitation appeared in the market. Under the conditions of densely built-up urban areas, these methods are of great current interest for city utilities. Quite different pipe renovation methods are used currently but the most popular method comprises the application of a flexible polymeric hose that makes it possible to form a new composite pipe inside the old one. The wall thickness of such a hose is among the important factors that have an impact on the cost and efficiency of pipe renovation methods based on the application of flexible polymeric hoses. The hose wall thickness is determined on the basis of calculating the "soil - old pipe - hose" system in view of its static stability. The article describes the technology for the trenchless rehabilitation of water pipes and the strength calculation method for a "pipe - polymeric hose" double-layer structure.
\end{abstract}

\section{Introduction}

Municipal pipelines of centralized water supply and wastewater disposal systems are among the most important and according to operating practice data, the most vulnerable elements of these systems [1, 2]. In this connection, reliability and environmental safety are the fundamental requirements for water pipes. Currently Russia ranks second in the world in terms of the length of underground pipelines, and in terms of pipe wear Russia also takes one of the top positions $[3,4,5]$. The overwhelming majority of water-supply pipes in Russian cities are made of steel, without any protection against internal and external corrosion; apart from that, they are considerably deteriorated and their condition is unsatisfactory [4-6].

${ }^{*}$ Corresponding author: tepper2007@yandex.ru 


\section{Methods and materials}

Over the past few decades, a new promising trend in the field of construction, repair and reconstruction of municipal water supply and wastewater disposal systems emerged in the world. This trend is named the trenchless technology [5-7]. Under the conditions of densely built-up urban areas, these methods are currently topical both for public utilities and for water consumers. In Russia since 2006 the percentage of water pipe construction and reconstruction through the application of trenchless technologies has been exceeding the percentage of traditional pipe-laying methods based on soil excavation [6,7]. At present over twenty basic methods for pipe trenchless renovation are used in Russian and foreign practice. For the implementation of this method, a hose is introduced inside a worn-out old pipeline through the manholes. This hose is made of a reinforcing material impregnated with a thermo-reactive binder (fiberglass cloth or synthetic felted fabric). Subsequently some heat-carrying agent (steam or hot water) is pressure-fed into the inner sealed jacket of the hose. As a result of this, the hose is smoothed out and pressed to the inner surface of the pipeline and the binder is polymerized, forming a new composite pipe. The pulling out and advancing of the hose inside the old pipe may be carried out with a flexible element (a wire rope) or under the pressure of a liquid or gaseous medium, or through a combined application of these two methods [7].

The main advantage of the hose pulling method is the provision of a simple and easy technology, simple and easy-to-get equipment for its implementation, a high-quality and long-lifetime protective coating, as well as a possibility to renovate sufficiently deteriorated pipelines (regardless the materials they are made of) of quite different diameters and lengths. The method is used for the application of a continuous protective coating onto the inner surface of pipes made of different materials and buried at any depth (either in soil or in nonaccessible crawlways) regardless the types of soil around the pipelines. The basic components of a polymer hose are the following: the carrying base having the shape of a hose; a reaction resin; some internal and external films, as well as special fillers that have no impact on the resistance of the resin to chemical and temperature loads. Unsaturated polyester resins as well as epoxy and vinyl-ester resins are predominantly used as reaction resins [810]. The method for pipe rehabilitation through the application of a flexible polymeric hose is the only technology that provides a tight adherence of a new pipe to the inner surface of rehabilitated pipes of different cross-section shapes (circular cross-section, oval crosssection, rectangular cross-section or curved cross-section) thus preserving their initial shapes [10]. Construction operations are carried out with the application of a closed method, i.e. tunneling and pipe laying are carried out with the use of micro-tunneling or horizontal directional drilling without any ground surface excavation in the soil body, where the initial displacements and soil compaction took place long ago, at the moment of this soil body formation, and the groundwater level is below the pipe bottom line [11, 12].

The key-factor influencing the choice of technological concepts for pipe rehabilitation both in water supply and wastewater disposal systems is the expected cost-level of repair and rehabilitation operations. Cost analysis requires taking into account both the cost of a pipeline running meter rehabilitation and its expected subsequent lifetime (depending on the selected rehabilitation method and the quality of executed work). Among the important factors influencing the cost of pipe rehabilitation with the application of a flexible polymeric hose is the thickness of the hose wall, which is determined based on the calculation of the "soil - old pipe - hose" system in view of its static stability. An excessively optimistic assessment of the old pipe condition or some underestimation of existing loads may result in the establishment of a statically unstable "soil - old pipe - hose" system. On the other hand, an unreasonable increase in a hose wall thickness results in a considerable increase in its cost. 


\section{Results and discussions}

The calculation is made for the two limit states:

- based on the condition of structural strength or stability, which failure may result in the pipeline breakage,

- for the deformations that may cause some deflections resulting in soil vault disturbance.

To assess the strength of a double-layer pipe structure "steel + polymeric hose", it is necessary to carry out the following four successive stages:

a) calculating the stability of a double-layer pipeline and determining the following factors:

- the variation range for the $R / d$ parameter for the known values of the residual thickness of deteriorated steel pipe (where $R=$ external radius of the pipe; $d=$ total wall thickness of a double-layer pipe);

- polymeric hose wall thickness ( with the relevant value of elasticity modulus);

- polymeric hose thickness adjusted to a metal in the context of stiffness;

b) strength calculation for tensile limit states in the bottom-line part of a double-layer pipeline;

c) strength calculation for the limit deformations (deflections) in the top line of a doublelayer pipeline;

d) testing the stability of a polymeric hose as an independent structure under the impact of external pressure (groundwater).

The checking up of observing the inequation is carried out based on the condition of the resistance to the impact of external hydrostatic pressure:

$$
P c r=\frac{E_{i} d^{3}}{4 R^{3}}{ }^{3} H_{i},
$$

Where $P_{c r}=$ critical load on the pipeline in view of its stability, $\mathrm{t} / \mathrm{m}^{2}$,

$E_{l}=$ steel pipe elasticity modulus, $21 \cdot 10^{6} \mathrm{t} / \mathrm{m}^{2}$,

$d=$ total thickness of the wall of a multi-layer pipe $\left(d=d_{s t}+d^{*}\right)$, comprising the residual thickness of the steel pipe $d_{s t}$ and the $d^{*}$ section of the polymeric hose, mm, adjusted to a metal in the context of stiffness and determined by the equation (2);

$R=$ external diameter of a multi-layer, $\mathrm{m}$ or $\mathrm{mm}$,

$H_{e}=$ the value of groundwater external pressure, $\mathrm{t} / \mathrm{m}^{2}$

(Note: if there is no any groundwater above the pipeline, then the depth of the pipeline location, from the ground surface to the pipe bottom line, is taken as $H_{e}$, as an extreme operating condition).

$$
d^{*}=d_{d}\left(E_{p l} / E_{s t}\right)
$$

Where $d_{d}=$ design (specified) thickness of the polymeric hose, $\mathrm{mm}$;

$E_{p l}=$ recommended compression elasticity modulus and recommended bending elasticity modulus of a polymeric hose; according to experimental data, it is taken within the range of $(15-50) \cdot 10^{4} \mathrm{t} / \mathrm{m}^{2}$;

$E_{s t}=$ steel elasticity modulus, $\mathrm{E}=21.0 \cdot 10^{6} \mathrm{t} / \mathrm{m}^{2}$;

The adjusted to metal value of the unit weight of a multi-layer pipeline is calculated by the equation (3):

$$
y^{*}=\left(y_{s t} d_{s t}+y_{p} d_{p}\right) /\left(d_{s t}+d_{p}\right)
$$

Where $y_{s t}=$ the unit weight of metal, $\mathrm{t} / \mathrm{m}^{3}$;

$y_{p}=$ the unit weight of plastic, $\mathrm{t} / \mathrm{m}^{3}$; 
The algorithm of strength calculation:

- the polymeric hose section $d^{*}$ (scaled to metal in the context of rigidity) is determined and the polymeric hose elasticity modulus value is taken from the proposed range;

- the total thickness of a multi-layer pipe wall $d=d_{s t}+d^{*}$ is determined;

- the range of $R / d$ correlation changes is determined;

- according to initial data, the relevant value of the pipe radius $R$ is taken, and the adherence to the requirements for the $R / d$ range is checked up; if the requirements are met, (i.e. the $R / d$ design value is within the established limits), then the calculation of strength is carried out; if the requirement is not met, then either the polymer hose thickness or the elasticity modulus values are increased within the recommended ranges.

The calculation based on strength conditions comprises the following:

1. Calculation of tensile stresses in the pipe bottom line resulting from the dead load of the pipe according to the following equation:

$$
\sigma_{\theta}=1,23 \gamma^{*} R\left(4 \frac{R}{d}-1\right),
$$

Where $R=$ pipe radius, $\mathrm{m} ; d=$ the wall thickness of a multi-layer pipe, $\mathrm{m} ; y^{*}=$ the unit weight of pipe material, $\mathrm{t} / \mathrm{m}^{3}$.

2. Calculation of compressive stresses resulting from groundwater external pressure by the formula:

$$
\sigma_{\theta}=-\gamma_{w} H_{w} \frac{R}{d}
$$

Where $\gamma_{w}=$ unit weight of groundwater that may be taken equal to $1 \mathrm{t} / \mathrm{m}^{3}$

$$
H_{w}=\text { groundwater level above the pipe bottom line, } \mathrm{m} \text {. }
$$

3. The calculation of stresses resulting from the internal pressure of pipeline water by the equation:

$$
\sigma_{\theta}=\frac{R}{d} \cdot P
$$

Where $P=$ internal pressure of pipeline water, $\mathrm{t} / \mathrm{m}^{2}$

4. The calculation of pipe bottom-line stresses resulting from the rock-pressure, taking into account the wheel pressure, according to the following formula:

$$
\sigma_{\theta}=\frac{R}{d}\left\{q_{1}-2 \frac{R}{d} \cdot S_{1}\right\},
$$

Where $\sigma_{\theta}=$ tangential stresses on the internal surface of the pipe bottom line, $\mathrm{t} / \mathrm{m}^{2}$;

$q_{1}, S_{1}=$ parameters of contact stresses, $\mathrm{t} / \mathrm{m}^{2}$, which are calculated by the equations (8), (9) and (10):

$$
q_{1}=-\frac{\frac{E_{1}}{E_{2}} \cdot\left(1+\mu_{2}^{*}\right)}{\frac{E_{1}}{E_{2}} \cdot\left(1+\mu_{2}^{*}\right)-\mu_{1}+\frac{R}{d}} P_{0},
$$




$$
\begin{gathered}
\alpha_{1}=3+\mu_{1}^{*}+4 \frac{R^{3}}{d^{3}}+\frac{E_{1}}{E_{2}} \cdot\left(5-\mu_{2}^{*}\right) \\
S_{1}=-\frac{\left(9-3 \mu_{2}^{*}\right) \cdot \frac{E_{1}}{E_{2}}}{\alpha_{1}} P_{2}
\end{gathered}
$$

Where $E_{1}=$ design elasticity modulus, $\mathrm{t} / \mathrm{m}^{2}$ (for a steel pipe $21 \cdot 10^{6} \mathrm{t} / \mathrm{m}^{2}$ );

$E_{2}=$ deformation modulus of a soil mass, $\left.\mathrm{t} / \mathrm{m}^{2}, E_{2}=1300 \mathrm{t} / \mathrm{m}^{2}\right)$;

$P_{0}, P_{2}=$ parameters of "compressible" load at the mine opening contour, $\mathrm{t} / \mathrm{m}^{2}$, calculated by the formula (11):

$$
P_{0}=\frac{1+\lambda}{2} \times \gamma H, P_{2}=\frac{1-\lambda}{2} \times \gamma H
$$

Where $\lambda=$ soil mass lateral pressure coefficient (the averaged value of 0.5 is taken), $\gamma=$ soil unit weight, $\mathrm{t} / \mathrm{m}^{3}$ (if relevant data is unavailable, it may be taken as $1.9 \mathrm{t} / \mathrm{m}^{3}$ );

$\mu_{1}{ }^{*}, \mu_{2}{ }^{*}=$ Poisson ratios for pipe material and soil (scaled for plain-strain conditions):

$\mu_{1}{ }^{*}=\mu_{1} /\left(1-\mu_{1}\right)$ and $\mu_{2}{ }^{*}=\mu_{2} /\left(1-\mu_{2}\right)$

$\mu_{1}, \mu_{2}=$ Poison ratios correspondingly for pipe (0.3) and soil $(0.35)$.

Wheel weight consideration for the structural design of rock pressure is carried out through the substitution of the unit weight of the cap-rock mass $\gamma$ with the adjusted unit weight $\gamma_{a d}$, calculated by the following equation (12):

$$
\gamma_{a d}=\frac{k \gamma H+\frac{19}{3+H}}{H}
$$

Where $H=$ the depth of the pipe bottom line, $\mathrm{m}$ (the depth is taken to the pipe bottom line and not to the pipe top line, in order to improve the calculation uniformity and the degree of safety);

$k \leq 1=$ the coefficient that takes into account the formation of rock-pressure load (is taken equal to 0.7 for $6<H \leq 10 \mathrm{~m}$, and equal to 1 for $H \leq 6 \mathrm{~m}$ ).

5. The total stresses $\Sigma \sigma_{\theta}$ in the pipe bottom line are calculated taking into account their sign ("+" = extension, "-" = compression) by the equations (4-7) and the inequation observance is checked up (13):

$$
\Sigma \sigma_{\theta}<R_{y}
$$

Where $R_{y}=$ the yield strength of steel, taken as $270 \mathrm{MPa}$.

If the inequation (13) is observed, the wall thickness of a multi-layer pipeline makes it possible to regard the pipeline as a self-supporting structure. If this inequation is not observed, the wall thickness of a multi-layer pipeline should be increased through an increase in the thickness of the plastic hose or through an increase in the plastic modulus of elasticity under the condition of a permanent hose thickness.

The calculation of deformations (deflections) comprises the following operations:

1. The calculation of pipe top-line deflections resulting from the pipe dead load by the following equation:

$$
U=2.74 \frac{1-\mu_{l}^{2}}{E_{l}} \gamma^{\prime} R^{2} \frac{R}{d}
$$


Where $U=$ the value of pipe top-line deflections (vertical shifts of the wall into the pipe), $\mathrm{m} ; E_{1}=$ the modulus of elasticity of a pipe material, $\mathrm{t} / \mathrm{m}^{2}\left(21.10^{6} \mathrm{t} / \mathrm{m}^{2}\right) ; \mu_{1}=$ Poisson ratio of pipe material $(0.3) ; \gamma^{*}=$ the adjusted unit weight of pipe material, $\mathrm{t} / \mathrm{m}^{3}$.

2. The calculation of pipe top-line deflections vs. the value of groundwater external pressure by the equation:

$$
U=\frac{2\left(1-\mu_{l}^{2}\right)}{E_{l}} \gamma_{w} H_{w} \frac{R}{d} R
$$

Where $U=$ the value of pipe top-line deflections (vertical shifts of the pipe wall into the pipe) as a result of groundwater presence, $\mathrm{m} ; H_{w}=$ the level of groundwater above the bottom line of the pipe, $m$.

3. The calculation of deformations resulting from the internal pressure of the water in the pipeline, taking into account the presence of groundwater by the following equation:

$$
U=\frac{2\left(1-\mu_{l}^{2}\right)}{E_{l}}\left(\gamma_{w} H_{w}-P\right) \frac{R}{d} R
$$

Where $U=$ the value of pipe top-line deflections (vertical shifts of the pipe wall) resulting from the external pressure and the compensating action of the internal pressure, $\mathrm{m} ; P=$ internal pressure, $\mathrm{t} / \mathrm{m}^{2}$ or w.c.m.

(Note: the negative value of the $U$ calculation value witnesses some suppositional straightening of possible deflections resulting from the impact of other destabilizing factors; when $U>0$, it is possible not to take the deflections into account, because they are obviously smaller).

4. The calculation of top-line deflections resulting from the rock pressure in the presence of wheel load by the following equation:

$$
U=-\frac{R^{2}}{E_{l} d}\left\{q_{l}+\frac{4 R^{2}}{3 d^{2}} \times S_{l}\right\}
$$

Where $U=$ the value of pipe top-line deflections under the impact of rock pressure, $\mathrm{m}$;

$q_{1}, S_{1}=$ parameters of contact stresses, $\mathrm{t} / \mathrm{m}^{2} ; \mathrm{E}_{1}=$ the modulus of elasticity of the metal, $\mathrm{t} / \mathrm{m}^{2}\left(21 \cdot 10^{6} \mathrm{t} / \mathrm{m}^{2}\right)$.

5. The pipe top-line deflection limits are determined. These limit deflections should not exceed the limit slopes and deformations of land surface. On the one hand, limit deflections should exclude any risk of pipe strength reduction due to its increased ellipticity, on the other hand, it should maintain the stability of ground-surface structures. The pipe top-line limit deflections are determined depending on the depth of pipe location (pipe bottom-line depth) $H(\mathrm{~m})$ by the equations (18 and 19) respectively:

$$
\begin{array}{r}
\text { Ul.sl. }=\frac{H}{3} \times\left[i_{n}\right] \\
\text { Ul.def. }=\frac{H}{1,7} \times\left[\varepsilon_{n}\right]
\end{array}
$$

Where $\left[i_{n}\right]=4.0 \times 10^{-3}-$ the limit slopes of land surface,

$\left[\varepsilon_{n}\right]=6.0 \times 10^{-3}-$ The limit deformations of land surface - taken on the basis of regulatory standards $[19,20]$. 
6. The total value of $\Sigma U$ deflections is calculated taking into account the signs "+" or "_." and the observance of inequations is checked up using the equations (20) and (21):

$$
\begin{aligned}
& \Sigma U<\text { Ul.sl. }=\frac{H}{3} \times\left[i_{n}\right] \\
& \Sigma U<\text { Ul.def. }=\frac{H}{1,7} \times\left[\varepsilon_{n}\right] *
\end{aligned}
$$

If both inequations, i.e. (20) and (21) are observed, the selected wall thickness of a multilayer pipe makes it possible to regard the pipeline as a self-supporting structure. If at least one inequation is not observed, the wall thickness of a multi-layer pipeline should be increased through an increase in the thickness of the polymeric hose or through an increase in its modulus of elasticity for a permanent hose thickness.

\section{Conclusions}

1. Unsatisfactory technical condition of water pipes in most Russian cities determines the importance and urgency of measures on their repair and renovation.

2. Under the conditions of densely built-up urban areas and congested underground space of modern cities, the most efficient method for pipe rehabilitation is the application of a flexible polymeric hose that makes it possible to form a new composite pipe inside the old one.

3. One of important factors influencing the cost of pipe renovation through the application of flexible polymeric hoses is the thickness of the pipe wall that is calculated on the basis of strength calculations for the "soil - old pipe - hose" system in view of its static stability.

\section{References}

1. S.V.Khramenkov, The Strategy of Water Supply Network Modernization (Stroyizdat Publishing House, 2005)

2. E.I.Pupyrev, O. G. Primin, Housing and Util. Compl. of Russia 5, 8-12 (2012)

3. O. G. Primin, Clean Wat.: Probl. and Solut., 3-4, 40-48 (2012)

4. O. G. Primin, Best Available Techn. for Wat. Supp. and Wastewat. Disposal J. 2, 232241 (2013)

5. V. Khramenkov, J. G. Primin, V. A. Orlov, The Reconstruction of Pipeline Systems (2008)

6. V. A. Orlov, E. V. Orlov. Trenchless Methods for the Construction, Reconstruction and Rehabilitation of Water Supply and Wastewater Disposal Networks (2007)

7. Y. S. Zakharov, Wat. Mag. J, 2 (102), 10-17 (2013)

8. DIN EN 1610 Laying and testing of sewer pipes and channels 32 (2011)

9. DIN EN ISO 11296-4-2011 Teil 4 Kunststoff rohrleitungssysteme fur die renovierung von erdverlegten entwasserungsnetzen freispiegelleitungen. 32 (2011)

10. ATV-DVWK-M 127- 2 Statische berechnung zur sanierung von abwasserkanalen und leitungen mit lining und montageverfahren (2000)

11. MCCS 6.01-03 Trenchless Pipe-Laying with the Application of Micro-Tunelling Systems and Pipe Reconstruction Using Special Equipment (The Resolution of the Moscow City Government \#530, 112, 2004)

12. RCS 40-303-2003 Trenchless Pipe-Laying with the Application of Micro-Tunneling Systems and Pipe Reconstruction Using Special Equipment (2003) 